\title{
NOTA SOBRE LA PRESENCIA DE ABATIA MEXICANA STANDL. (SALICACEAE) EN EL ESTADO DE GUERRERO, MÉXICO
}

\author{
Nelly Diego Pérez y y Martha Martínez Gordillo² \\ ${ }^{1}$ Universidad Nacional Autónoma de México, Facultad de Ciencias, Laboratorio de \\ Plantas Vasculares. Ciudad Universitaria, 04510 México, D.F. \\ ${ }^{2}$ Universidad Nacional Autónoma de México, Herbario de la Facultad de Ciencias \\ Apdo. Postal 70-399, 04510 México, D.F.
}

\section{RESUMEN}

Se da a conocer por primera vez la presencia de Abatia mexicana Standl. en el estado de Guerrero, donde crece en el bosque mesófilo de montaña. Se mencionan sus características distintivas, se proporciona información acerca de su distribución geográfica y fenología.

Palabras clave: Abatia, Guerrero, México, Salicaceae.

\begin{abstract}
Abatia mexicana Standl. is reported for the first time from Guerrero. Its distinctive characters are indicated, and information on its geographic distribution and phenology are provided.
\end{abstract}

Key words: Abatia, Guerrero, México, Salicaceae.

\section{INTRODUCCIÓN}

Durante las colectas realizadas en el estado de Guerrero se encontró Abatia mexicana Standl., especie endémica de México. Este género pertenece a la familia Salicaceae, aunque con anterioridad era ubicado dentro de Flacourtiaceae, familia que no es considerada monofilética en clasificaciones actuales (Judd et al., 2002; APGII, 2003). Se distribuye principalmente en las regiones tropicales de Centro y Sudamérica, donde se localizan ocho de las nueve especies conocidas del mismo. 
Se distingue fácilmente de los otros géneros de la familia por presentar hojas opuestas y pelos estrellados.

Abatia mexicana Standl. Publ. Field Mus. Bot. 8: 318. 1931. Tipo: México, Veracruz, Liebmann 15030 (F). Fig. 1.

Arbusto o árbol de (.90-)1.40-5 m, indumento de pelos estrellados. Hojas opuestas, 5-16 x 2.5-6.5 cm, lanceolado-ovadas, ápice acuminado, margen serrado, glandular, base redondeada o ligeramente subcordada, haz esparcidamente peloso, sobre todo en las venas, envés pubescente, con pelos estrellados, sésiles o estipitados, nervación pinnada; pecíolo 0.7-2.1 cm. Inflorescencias en racimos 8-15 cm, terminales o axilares; pedúnculo $5 \mathrm{~cm}$, estrellado-pubescente. Flores bisexuales, verdes claras o amarillas; pedicelos 2-5 $\mathrm{mm}$; cáliz gamosépalo, sus lóbulos lanceolado-ovados, glabros en la cara adaxial, estrellado-pubescentes en la cara abaxial; pétalos ausentes; estambres 8, filamentos glabros; estaminodios numerosos, filiformes, glabros; ovario híspido-pubescente, estilos glabros. Fruto una cápsula ovoide, dehiscente, pubescente. Semillas $1 \mathrm{~mm}$, ovoides, negras, costilladas longitudinalmente.

Ejemplares examinados: Guerrero, Mpio. Malinaltepec: Tres Marías, 1707'57.6" N, 9841'45.5" W, 2220 m, 24-nov-2004, N. Diego y R. de Santiago 9583 (FCME); Tres Marías, 1707'57.1" N, 9841'42.2" W, 27-ene-2006, M. Bazán et al. 18 (FCME).

Distribución. Se conoce únicamente de los estados de Oaxaca, Puebla, Veracruz y Guerrero. Se encuentra en altitudes de 1050 a 2220 m. En Guerrero se colectó en bosque mesófilo de montaña, sin embargo en otras entidades de la República se le encuentra también en bosques de Quercus, ya sea puros o mixtos, en bosque de Pinus y en matorrales (Fig. 2).

Fenología. En Guerrero, florece y fructifica de octubre a noviembre, aunque en los otros estados donde se distribuye se ha colectado con estructuras reproductoras en un período más amplio: de marzo a octubre. En la mayoría de los casos se le registra como arbusto, sólo en Guerrero y una localidad de Veracruz (Nee, 1999) se habla de un arbolito.

En Guerrero, Abatia mexicana se encuentra bien representada en bosque mesófilo de montaña perturbado, con Edithea, Xylosma, Ficus y otros, tanto en cañadas como lomeríos, en suelo arcilloso con gran abundancia de rocas. 


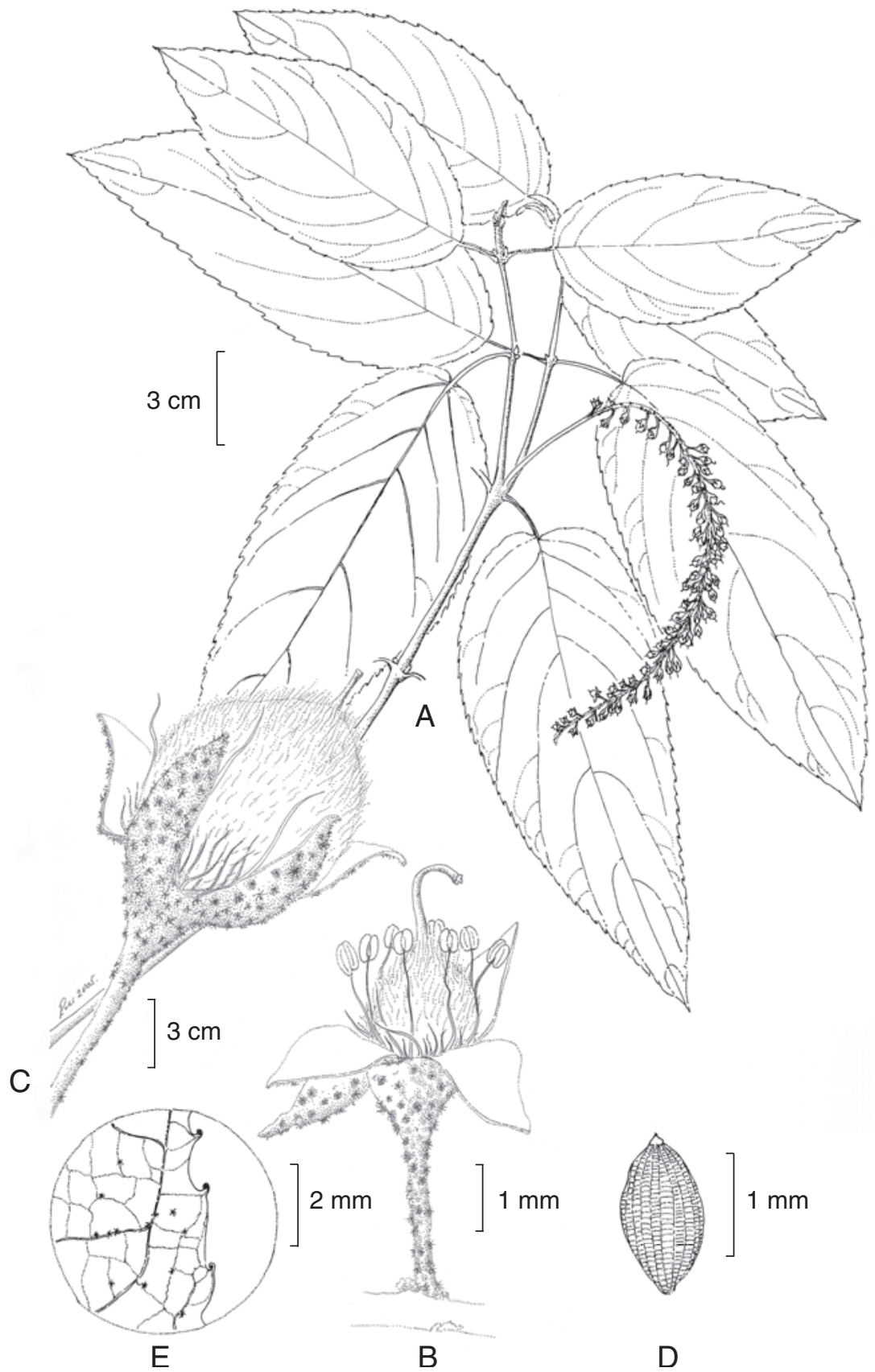

Fig. 1. Abatia mexicana Standl. A. rama con hojas e inflorescencia; B. flor mostrando estambres y pubescencia; C. fruto; D. semilla; E. detalle del margen de la hoja. 


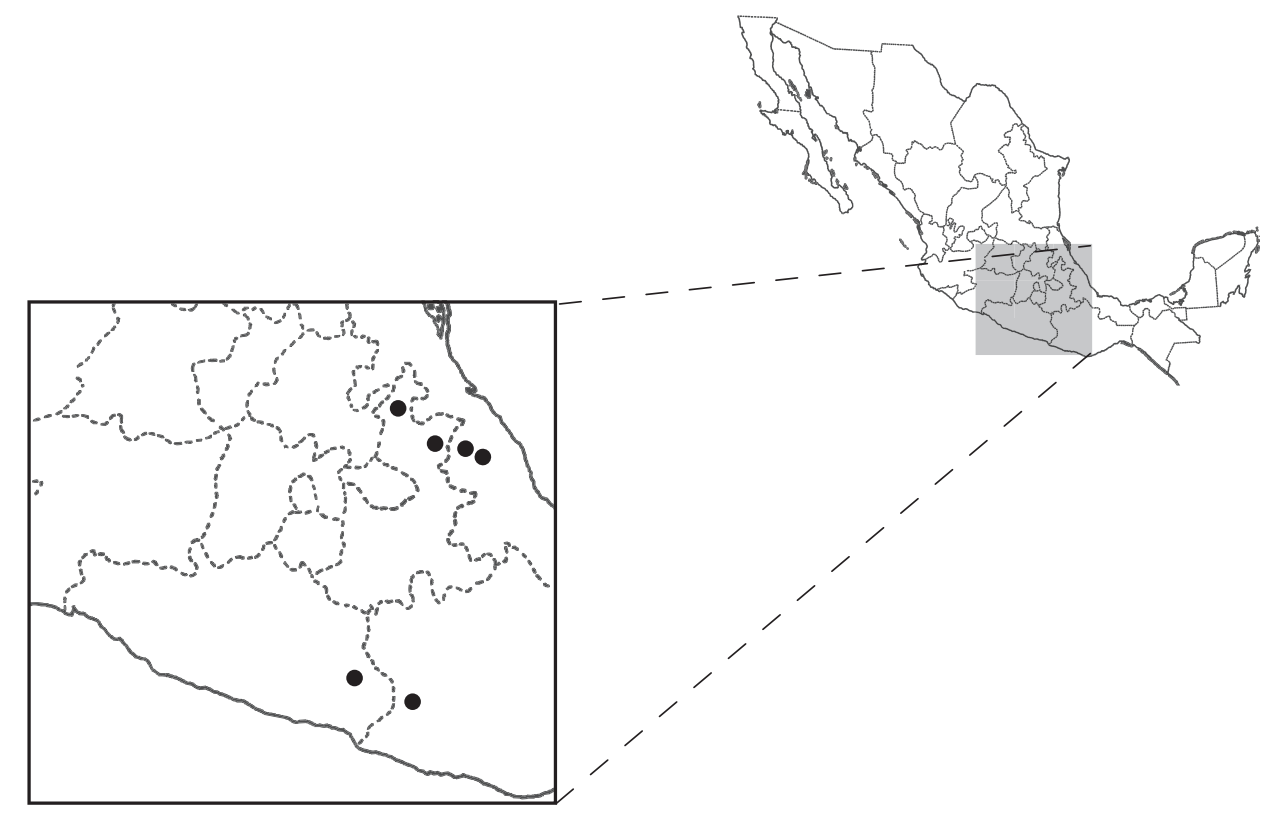

Fig. 2. Mapa que muestra la distribución de Abatia mexicana.

Se trata de un estrecho endemismo, porque la localidad en donde se recolectó se encuentra cerca de los límites con el estado de Oaxaca y también es probable que se presente en Hidalgo, estado colindante con Veracruz y Puebla.

\section{AGRADECIMIENTOS}

Se agradece al Dr. Jerzy Rzedowski por la revisión crítica del manuscrito y a Ramiro Cruz por la ilustración.

\section{LITERATURA CITADA}

APGII, 2003. An update of the angiosperm phylogeny group classification for the orders and families of flowering plants: APGII. Bot. J. Linn. Soc. 141: 399-436.

Judd, W. S., C. S. Campbell, E. A. Kellogg, P. F. Stevens y M. J. Donoghue. 2002. Plant systematics, a phylogenetic aproach. Sinawer Associates. Sunderland, MA. 576 pp. 
Diego y Martínez: Presencia de Abatia mexicana en Guerrero

Nee, M. 1999. Flacourtiaceae. In: Sosa, V. y A. Gómez-Pompa (eds.). Flora de Veracruz 111. Instituto de Ecología, A. C. Xalapa, Ver. 79 pp.

Recibido en mayo de 2006.

Aceptado en agosto de 2006. 